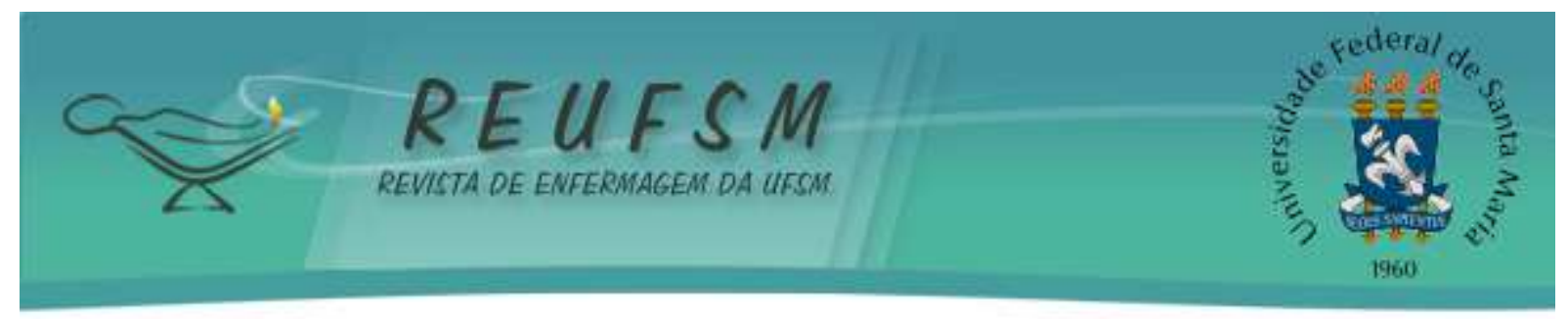

\title{
HOMENS APÓS CIRURGIA MUTILADORA NO SISTEMA GENITURINÁRIO: CONTRIBUIÇÕES A PARTIR DE HEIDEGGER E OREM*
}

\author{
MEN AFTER MUTILATING SURGERY IN GENITOURINARY SYSTEM: \\ CONTRIBUTIONS FROM HEIDEGGER AND OREM
}

\section{HOMBRES DESPUÉS DE LA CIRUGÍA MUTILADORA EN SISTEMA GÉNITO- URINARIO: CONTRIBUICIONES DE HEIDEGGER Y OREM}

\author{
Rafael Carlos Macedo de Souza ${ }^{1}$ \\ Anna Maria de Oliveira Salimena ${ }^{2}$ \\ Heloisa Campos Paschoalin ${ }^{3}$ \\ Ívis Emília de Oliveira Souza ${ }^{4}$
}

Doi: $10.5902 / 2179769230186$

RESUMO: Objetivo: desvelar sentidos do homem ao desenvolver autocuidado após cirurgia mutiladora no sistema geniturinário e articular reflexões com a Teoria de Orem. Método: pesquisa de natureza qualitativa com abordagem fenomenológica fundada no pensamento e método de Martin Heidegger. Participaram 13 homens que realizaram procedimento cirúrgico mutilador da próstata, testículo ou pênis em um Hospital Universitário da Zona da Mata Mineira. Os depoimentos, acessados durante os meses de junho e agosto de 2016, foram analisados à luz dos conceitos propostos por Heidegger e da Teoria de Orem. Resultados: significaram a necessidade de se cuidar e tomaram para si a responsabilidade de cuidado consigo. Da análise compreensiva emergiu a Unidade de Significação: entender que é necessário ter cuidado durante o tratamento e fazer acompanhamento. Considerações finais: os homens adquirem uma rotina de autocuidado, após serem lançados na facticidade de enfrentar uma cirurgia mutiladora no sistema geniturinário.

Descritores: Saúde do homem; Sistema urogenital; Amputação; Autocuidado; Filosofia em enfermagem

ABSTRACT: Aim: to reveal the man's senses while developing self-care after mutilating surgery in genitourinary system and articulate thoughts with Orem'sTheory. Method: qualitative research, with phenomenological approach, based on the thought and method of Martin Heidegger. Thirteen men that performed surgical mutilating procedure of prostate, testicles or penis at a University Hospital of Zona da Mata of Minas Gerais participated in the study. The statements, accessed during June and August 2016, were analyzed in the light of the concepts proposed by Heidegger and Orem's Theory. Results: they realized the need to care for themselves and assumed the responsibility of self-care. From comprehensive analysis, the Meaning Unit emerged: to understand

\footnotetext{
* Recorte da dissertação "sentidos do ser-aí-homem-após-cirurgia-mutiladora-do-sistema-geniturinário: contribuições para o cuidado à saúde do homem” apresentada ao Programa de Pós-Graduação Mestrado em Enfermagem da Universidade Federal de Juiz de Fora

${ }^{1}$ Enfermeiro. Mestre em Enfermagem. Universidade Federal de Juiz de Fora. Juiz de Fora, MG, Brasil. E-mail: rafaelcarlos_souza@hotmail.com

${ }^{2}$ Enfermeira. Doutora em Enfermagem. Universidade Federal de Juiz de Fora. Juiz de Fora, MG, Brasil. E-mail: annasalimena@terra.com.br

${ }^{3}$ Enfermeira. Doutora em Enfermagem. Universidade Federal de Juiz de Fora. Juiz de Fora, MG, Brasil. E-mail: hcpaschoalin@gmail.com

${ }^{4}$ Enfermeira. Doutora em Enfermagem. Universidade Federal do Rio de Janeiro. Rio de Janeiro, RJ, Brasil. Email: ivis@superig.com
} 


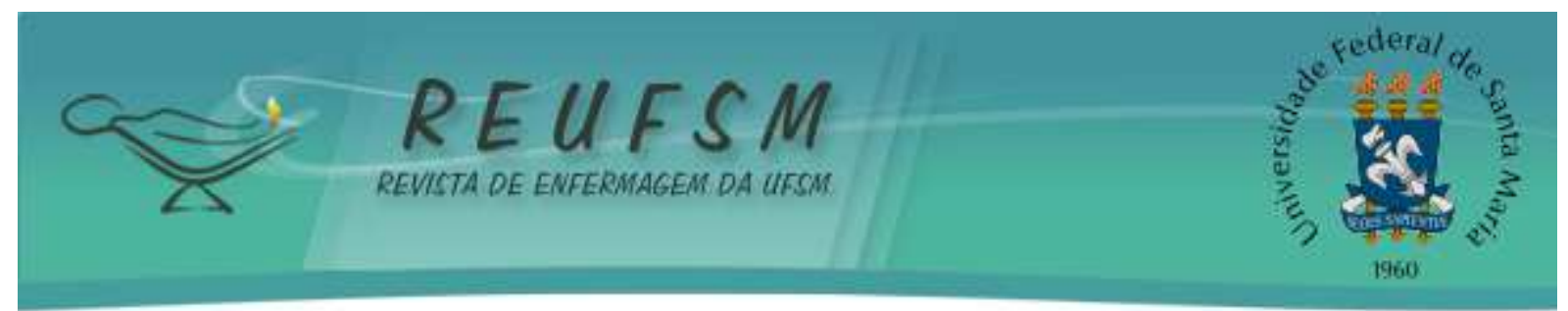

that care is necessary during treatment, as well as follow-up. Final thoughts: men acquire a selfcare routine, after facing the need for a mutilating surgery in the genitourinary system.

Descriptors: Men's health; Urogenital sytem; Amputation; Self care; Philosophy, Nursing

RESUMEN: Objetivo: revelar los sentidos del hombre al desarrollar el autocuidado, después de la mutilación de la cirugía en el sistema génito-urinario y articular reflexiones con la teoría de Orem. Método: investigación cualitativa con perspectiva fenomenológica fundamentada en el pensamiento y en el método de Martin Heidegger. Participaron 13 hombres que realizaron el procedimiento quirúrgico mutilador en próstata, testículos o pene en un Hospital Universitario de la Zona da Mata de Minas Gerais. Las declaraciones, recolectadas entre los meses de junio y agosto de 2016, fueron analizadas por medio de los conceptos propuestos por Heidegger y la teoría de Orem. Resultados: significaron la necesidad de cuidar de sí mismos y asumieron la responsabilidad del autocuidado. Del análisis de la comprensión se evidenció la Unidad de Significación: entender que es necesario tener cuidado durante el tratamiento y hacer acompañamiento. Consideraciones finales: los hombres adquieren una rutina de cuidado de sí mismos, después de la necesidad de una cirugía mutiladora del sistema genitourinario.

Descriptores: Salud del hombre; Sistema urogenital; Amputación; Autocuidado; Filosofía en enfermería

\section{INTRODUÇÃO}

Nos aspectos relacionados à saúde, ao contrário do que se observa nas demais esferas sociais, o homem aparece com uma trajetória desfavorecida. ${ }^{1}$ Estudos apontam para um déficit de comportamento para fins preventivos, uma baixa procura aos serviços de atenção básica a saúde, expressiva exposição à violência e um maior índice de morbidade e mortalidade relacionadas a esta parcela da população. ${ }^{1-5} \mathrm{O}$ desfavorecimento, nessa trajetória, ocorre pelo comportamento do homem, pautado no modelo esperado pela masculinidade hegemônica, em que associa sua essência às regras atribuídas pela sociedade, de sujeito ativo, forte, viril, reservado emocionalmente e que não adoece. Agindo deste modo, pressupõe um distanciamento do comportamento esperado pelas mulheres, enraizado nos sentimentos e no cuidado de si e dos outros. ${ }^{6-7}$

Buscando reverter o aspecto que associa o homem a um descuidado consigo, dentre outros, foi lançada no ano de 2009, no Brasil, a Política Nacional de Atenção Integral à Saúde do Homem. Por meio desta iniciativa, espera-se que àqueles que estão na faixa etária de 20 a 59 anos também possuam ações programáticas próprias, almejando a melhoria na assistência oferecida, assim como a promoção de mudança cultural e sobre o cuidado de si, reconhecendo os aspectos desta população como problema de saúde pública. ${ }^{1}$

Atualmente, o autocuidado do homem não é realizado como proposto pelo sistema de saúde, pautado na prevenção e promoção à saúde. ${ }^{1,3,5}$ Assim, ocorre a invisibilidade masculina 


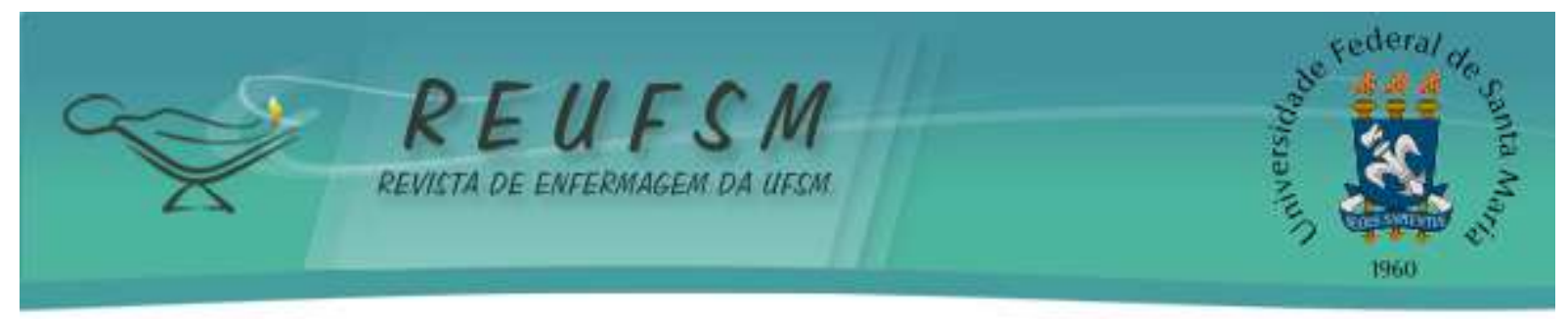

nos serviços de saúde, sendo estes considerados como espaços feminilizados que, muitas das vezes, reproduzem e reforçam esta situação. ${ }^{8}$

Faz-se necessário que haja uma desconstrução no estereótipo de que o homem não realiza seu autocuidado, a partir da sensibilização dos profissionais de saúde sobre as inúmeras demandas masculinas, sobretudo as questões de gênero, adoecimento e saúde. É possível que ocorra, por meio de ações voltadas para saúde do homem, um avanço na promoção e na busca por cuidado, tornando os próprios homens protagonistas neste processo. ${ }^{9}$

Acredita-se que o enfermeiro possa desempenhar importante papel na ressignificação do autocuidado masculino, especialmente frente a um processo de adoecimento que implica em cirurgia mutiladora no seu órgão genital-urológico.

A enfermagem considera as subjetividades e o contexto sociocultural ao prestar sua assistência. Portanto, é possível que em todas as redes de atenção à saúde, sejam realizadas atividades de promoção para o crescimento educativo do homem frente ao seu processo de adoecimento, auxiliando-o a enfrentar as mudanças no dia a dia, advindas da intervenção cirúrgica.

Neste contexto, Dorothea Orem, em 1995, publicou a quinta edição de sua obra intitulada Nursing: Concepts of practice. ${ }^{10}$ A teorista acredita que os indivíduos possuem a possibilidade de aprender e se desenvolver. Desta maneira, o autocuidado é um comportamento aprendido e não instintivo. Quando o indivíduo não é capaz de aprender e desenvolver autocuidado, outros devem proporcioná-lo. Este é o papel da enfermagem, desenvolver assistência às pessoas, almejando proporcionar cuidados de saúde quando estas são incapazes, acreditando no desenvolvimento e no bem-estar do indivíduo. ${ }^{10}$

A teoria de Orem denominada de teoria do déficit de autocuidado, engloba três teorias que são inter-relacionadas: do autocuidado, do déficit de autocuidado e dos sistemas de enfermagem. A teoria do autocuidado esclarece que o autocuidado é a capacidade que o indivíduo possui de desenvolver atividades para promoção do próprio cuidado, podendo ser afetado por inúmeros condicionantes básicos como o sexo, estado de saúde e padrão de vida. ${ }^{10-11}$

Na teoria do déficit de autocuidado, delineia-se a necessidade do cuidado da enfermagem, necessitando esta assistir quando as pessoas apresentam dificuldades ou não são capazes de realizálo, sobretudo nas limitações inerentes às condições do processo saúde-doença. Orem apresenta cinco métodos de ajuda: agir ou fazer para outra pessoa; guiar e orientar; proporcionar apoio físico e psicológico; manter ambiente que promova o desenvolvimento pessoal; ensinar. ${ }^{10-11}$ 


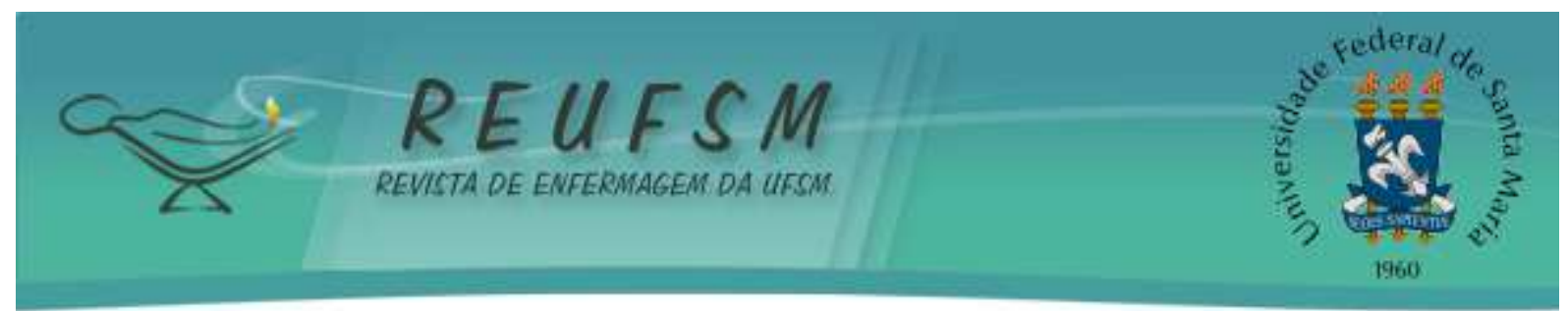

Após a definição de autocuidado e da explanação sobre quando a enfermagem é necessária, Orem determina a partir da teoria dos sistemas de enfermagem, como direcionar a assistência para preencher os requisitos de autocuidado do paciente por meio de três sistemas: totalmente compensatório, parcialmente compensatório e o de apoio-educação. No sistema de apoio-educação, a pessoa realiza seu autocuidado com orientações e estimulo do enfermeiro, visando à aquisição de novas habilidades. ${ }^{10-11}$

Esta investigação justifica-se, pois o enfermeiro, como educador e provedor para o autocuidado, pode identificar as demandas de cuidado e conduzir suas ações pautadas na capacidade do próprio homem em desempenhá-las. A necessidade de suporte e orientação do enfermeiro ocorre nas mais diversas situações, estendendo-se para além da doença e da intervenção cirúrgica, pois a assistência prestada precisa auxiliar também no momento da recuperação pós-operatória e nas consequências advindas com o processo cirúrgico. ${ }^{10-11}$

Com a realização do procedimento cirúrgico, abre-se um campo de possibilidades para atuação do enfermeiro, conforme observado em estudos realizados com homens que vivenciam o câncer de pênis e de próstata, o tratamento e a possibilidade de amputação dos órgãos são considerados como um grande fator de impacto na sexualidade, autoimagem e autoestima, modificando sua vida sexual, afetiva e social e, como consequência, implicando na perda da virilidade, o que é tido como a essência masculina. ${ }^{12-13}$

Dessa maneira, emergiu o questionamento da pesquisa: como é realizado o autocuidado de homens após se submeteram à cirurgia mutiladora no sistema geniturinário? Considerando que tais procedimentos impactam consideravelmente no modo de viver, tornou-se objeto desta investigação as vivências do homem após cirurgia mutiladora no sistema geniturinário e o objetivo delineado foi desvelar sentidos do homem ao desenvolver autocuidado, após cirurgia mutiladora no sistema geniturinário e articular reflexões com a Teoria de Orem.

\section{MÉTODO}

Trata-se de investigação de natureza qualitativa, com abordagem fenomenológica. Busca-se desvelar o fenômeno, a maneira como ele se mostra originalmente, como ele é em si mesmo e fundamentado no pensamento e método de Martin Heidegger, filósofo existencialista, para compreender os significados e sentidos do ser, como a possibilidade de desvelar o fenômeno em estudo. ${ }^{14} \mathrm{O}$ cenário foi um Hospital Universitário localizado na Zona da Mata 


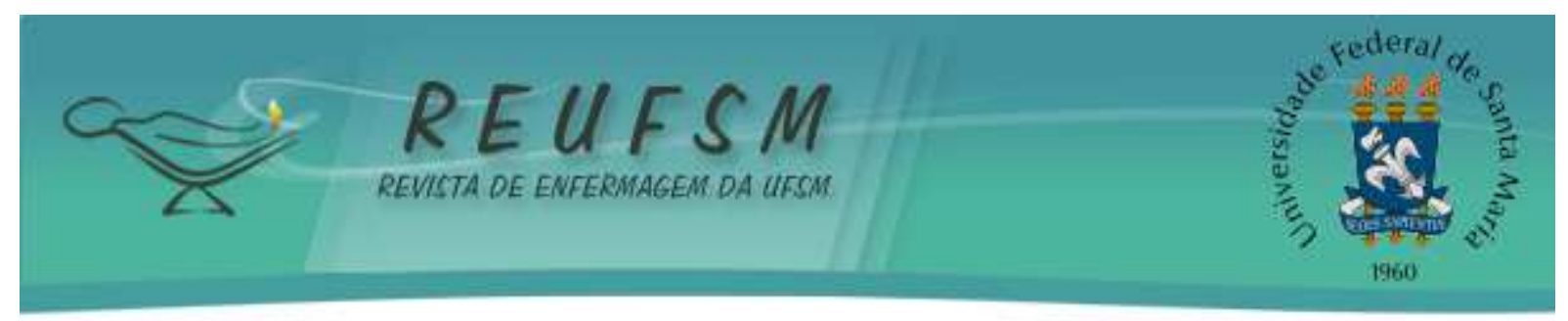

Mineira, Brasil. Este possui um trabalho de excelência que abarca o ensino, a pesquisa, a extensão e é considerado referência para o atendimento a pacientes do Sistema Único de Saúde.

Os critérios de inclusão delineados foram homens submetidos a procedimento cirúrgico mutilador da próstata, testículo ou pênis nos anos de 2014 e 2015, com idade maior que 18 anos, e de exclusão, os sem condições psicoemocionais para prestar informações. $\mathrm{O}$ recorte temporal para realização do procedimento cirúrgico foi para que os homens entrevistados já tivessem superado as dores próprias do pós-operatório e pudessem responder sobre o seu cotidiano com o que de novo se mostrou, em decorrência da cirurgia.

Participaram do estudo 13 homens, sendo que o número de participantes não foi preestabelecido, pois como a etapa de campo foi desenvolvida concomitantemente com a análise dos depoimentos, este número foi satisfatório. A partir de seus depoimentos, foi possível alcançar os significados do fenômeno proposto e do objetivo delineado, indicando o momento de encerrar a coleta dos depoimentos. Com vistas à preservação do anonimato dos homens, estes foram identificados com o código alfanumérico "E" de entrevistados e seguidos com a numeração das entrevistas na ordem em que foram realizadas, como exemplo E1, [...], E13.

Utilizando os registros do Serviço de Arquivo Médico do hospital, foi possível identificar os prováveis participantes e, após agendamento telefônico, o encontro foi realizado na casa dos próprios homens entre os meses de junho a agosto de 2016. O modo de acesso aos depoentes foi a entrevista fenomenológica. Buscou-se, inicialmente, desenvolver uma conversa descontraída e uma aproximação, observando o modo de falar e agir para, posteriormente, mediado pela empatia e intersubjetividade, iniciar a coleta do depoimento com a questão norteadora: Como está o seu dia a dia após a cirurgia? ${ }^{14}$

Mediante o consentimento dos participantes, os depoimentos foram gravados em áudio e transcritos na íntegra, com fidedignidade à fala original. Com a escuta e leitura atentiva, os trechos da entrevista foram destacados buscando as estruturas essenciais expressas. Foram desenvolvidos os dois momentos metódicos propostos pelo referencial de Martin Heidegger, descrito no livro Ser e Tempo: análise compreensiva e análise interpretativa. ${ }^{14}$

A análise compreensiva começou com a construção das Unidades de Significação (USs) a partir das estruturas essenciais que emergiram nos depoimentos. Com os caputs dessas USs, obteve-se o conceito de ser que abriu a possibilidade de apreender alguns sentidos de ser para a elaboração da análise interpretativa. ${ }^{14}$ Este artigo apresenta a US 


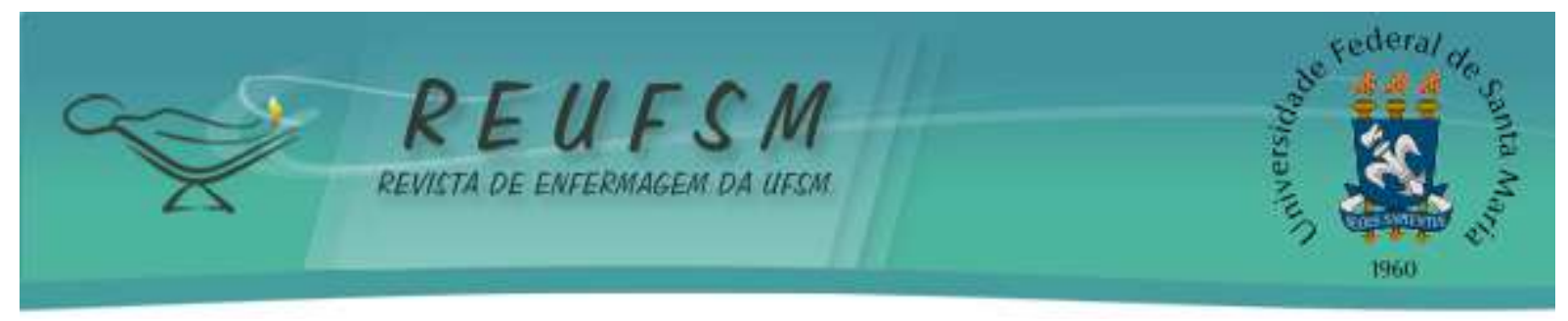

apreendida que revela o cuidado adquirido pelos homens após cirurgia mutiladora na próstata, testículo e pênis, à luz dos conceitos propostos por Heidegger e da Teoria de Orem.

O projeto de pesquisa foi aprovado em 05 de maio de 2015 pelo Comitê de Ética e Pesquisa com Seres Humanos do Hospital Universitário da Universidade Federal de Juiz de Fora, com o parecer favorável de número 1.049.543 e Certificado de Apresentação e Apreciação Ética (CAAE) de número 41459114.0.0000.5133. Todos os padrões éticos das pesquisas com seres humanos exigidos pela Resolução $466 / 12$ foram respeitados. ${ }^{15}$

\section{RESULTADOS}

Foram entrevistados 13 homens sendo que destes, um realizou cirurgia de amputação do pênis, três do testículo e nove da próstata. As idades oscilaram entre 18 e 75 anos e, para oito dos depoentes, esta foi a primeira intervenção cirúrgica vivenciada.

A partir dos depoimentos dos homens emergiu a US: "Entender que é necessário ter cuidado durante o tratamento e fazer acompanhamento".

Os homens significaram que foi e que é necessário se cuidar, pois tiveram que fazer acompanhamento de saúde, biópsia, exames, comparecer às consultas no dia certo, tomar os remédios, fazer os preparos para cirurgia e, por vezes, fazer tratamento com radioterapia e quimioterapia.

Um cuidado comigo. [...] Tive que fazer os PSA (Antígeno Prostático Específico), acompanhamento, as consultas e comparecer no dia certo, fazer os exames, o tratamento de radioterapia também. (E1)

Tive que fazer um monte de exame, muito exame! (E3)

Cheguei a fazer tratamento de quimioterapia depois. (E4)

Fiz biópsia e tive que fazer aquele preparo todo para cirurgia. (E5)

Depois teve que fazer radioterapia. (E8)

Tomo os remédios conforme mandou tomar, direitinho! (E10)

Houve o reconhecimento de que é necessário fazer os exames e iniciar o tratamento desde o começo. Assim, eles fazem tudo o que é indicado e aconselham irmão e amigos a procurar o médico e fazer o exame de toque, pois este é tido como essencial. Eles continuam acreditando que é necessário fazer acompanhamento e exames de PSA (Antígeno Prostático Específico). Desta forma, eles têm esperanças de ficarem curados. 


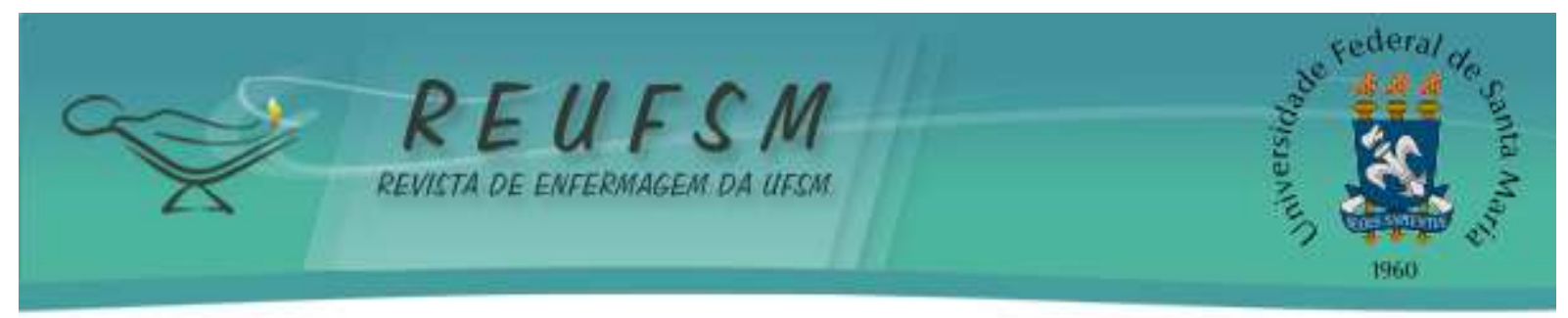

Eu sei que terei que fazer acompanhamento pelo resto da vida, mas eu tenho a esperança de curar este câncer! (E1)

Tenho que fazer outro PSA para ver se houve alguma mudança. (E5)

Depois que eu operei, eu aconselho muita gente, irmão, amigo, vá procurar um médico. [...] Vai lá fazer o toque. [...] Não deixa de fazer, porque isso é o essencial. [...] Faz muito exame! Fez e não constatou nada não, tudo bem! (E7)

Depois da cirurgia, tudo que eles mandam, eu faço! Eu estou fazendo direitinho! (E9)

O câncer que estava na próstata desceu para esta perna aqui. Ai eu estou fazendo o tratamento. (E10)

\section{DISCUSSÃO}

Com o compreendido, anuncia-se a possibilidade de desvelar alguns sentidos do seraí-homem-após-cirurgia-mutiladora-no-sistema-geniturinário. ${ }^{14}$

Inicialmente, vive na facticidade de estar lançado em uma condição que não foi escolhida e que não houve a opção de fugir. Assim, vivencia uma nova cotidianidade de cuidados e esta é a maneira como se encontra, na maioria das vezes, imerso no seu dia a dia. ${ }^{14}$

Nesta cotidianidade, o ser-aí-homem-após-cirurgia-mutiladora-no-sistema-geniturinário encontra-se no modo do falatório, ao utilizar termos em sua linguagem habitual que entendia, porém que não compreendia, como radioterapia, biópsia e quimioterapia. Nesta concepção, repete o que os outros falaram, mantendo-se numa compreensão e dialeto que não lhes são próprios. Afirma que o exame de toque é essencial, repetindo o que os outros dizem revelando, assim, uma compreensão inconsistente sobre o que se expressa, sendo um modo impróprio de ser pois apenas passa adiante um discurso pronto. ${ }^{14,16}$

Após a intervenção cirúrgica, o cuidado no que tange aos aspectos relacionados à saúde que, muitas das vezes, o ser-aí-homem-após-cirurgia-mutiladora-no-sistemageniturinário deixa de lado, foi retomado. Foi necessário ir às consultas, fazer acompanhamento da saúde e tomar remédios, quando então assume para si a responsabilidade de cuidado, revela o modo de ser da preocupação e busca a possibilidade da cura.

Preocupação e cura são conceitos que se mostram interligados e sempre estão presentes na existência do ser-aí-homem-após-cirurgia-mutiladora-no-sistema-geniturinário, ambos possuem em sua essência a demonstração de cuidado que é própria do ser-aí consigo mesmo ou com outros ser-aí, também chamados de co-presença. ${ }^{14,17}$ 


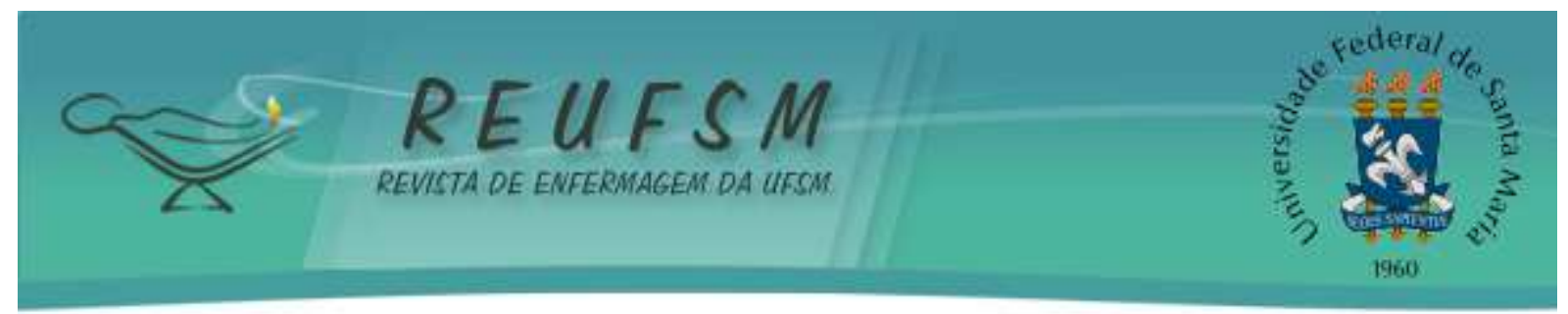

Neste modo de ser, quando se ocupa das coisas e se preocupa consigo, abre-se para seu poder-ser mais próprio, assumindo, portanto, o sentido da propriedade e da autenticidade. No modo de ser-com, expressa preocupação e solicitude com os outros que estão ao redor no seu mundo circundante, aqueles que se encontram mais próximos, como os familiares e amigos. Assim, demonstra um modo de cuidado, não apenas consigo, mas também de cuidar da existência dos outros ser-aí. ${ }^{14,17}$

O homem constantemente busca reafirmar sua masculinidade, escondendo suas emoções e negando situações de dor. Desta maneira, posterga consultas, exames e adesão a métodos preventivos, sendo o tratamento das doenças realizado apenas ao alcançar o limite suportável por seu organismo. Observa-se um descuidado do homem para consigo ao reconhecer e buscar ajuda quando percebe os primeiros sinais e sintomas decorrentes de doenças, como o câncer de pênis e de próstata, enfermidades que podem causar a amputação do órgão. ${ }^{18-19}$

Estudos apontam que quando os homens se deparam com uma situação de doença ou mesmo um tratamento cirúrgico, eles apresentam uma nova rotina de cuidados, enfatizando que não mais irão subestimar doenças e pautar suas ações na busca pela masculinidade, mas sim almejando uma melhor condição para sua saúde. Dessa forma, afirmam o desenvolvimento de autocuidado ao se preocupar com o próprio corpo e com o surgimento de novos sinais ou sintomas, enfatizando a necessidade de uma busca rápida por ajuda, sem deixar a saúde como algo secundário. ${ }^{19-20}$

Nesta investigação, encontrou-se respaldo para estas assertivas, pois com a intervenção cirúrgica, os homens ressignificaram o cuidado consigo e abriram possibilidades para o autocuidado, além de uma solicitude com o cuidado ao outro. ${ }^{14}$ Neste contexto, pensando na rotina de cuidados dos homens após uma cirurgia mutiladora na próstata, testículo e pênis, o enfermeiro pode fundamentar sua assistência na teoria de Orem. ${ }^{10-11}$ Por meio das ações de enfermagem, é possível que ocorra o estímulo para que os homens adotem e mantenham atitudes de promoção e manutenção da vida e da saúde.

Refletindo sobre a teoria do autocuidado, observa-se a presença de alguns condicionantes básicos que afetam a saúde masculina como ser homem, estar no pósoperatório de uma cirurgia mutiladora e o padrão de vida característico desta população.

Assim, ser pós-operado implica diversas limitações que abrem possibilidades para o cuidado da enfermagem, conforme explicitado na teoria do déficit do autocuidado. A partir 


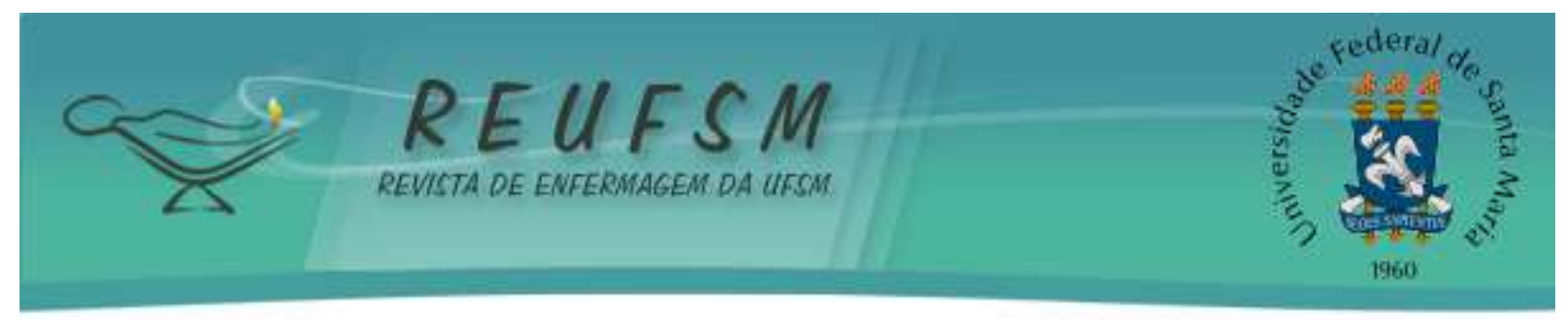

dos métodos de ajuda propostos, o enfermeiro pode agir ou fazer para o homem, guiar e orientar, oferecer apoio físico, psicológico e proporcionar um ambiente que promova o desenvolvimento pessoal e ensinar. ${ }^{10-11}$

Portanto, é por meio do sistema de apoio-educação, que compõe a teoria dos sistemas de enfermagem, que este processo pode tonar-se eficaz. As informações e capacitações para o autocuidado recebidas do enfermeiro devem orientar para o tratamento efetivo, para a adesão ao uso dos medicamentos propostos, para a importância das consultas, do acompanhamento e dos cuidados terapêuticos gerais. ${ }^{10-11}$ Desta maneira, permite que ocorra a prevenção das complicações resultantes do pós-operatório, assim como diminui as possibilidades de recidivas do câncer e de outras doenças que possam ter ocasionado a mutilação.

\section{CONSIDERAÇÕES FINAIS}

Identificou-se que os homens após lançados na facticidade de enfrentar uma intervenção cirúrgica no sistema geniturinário, retomam uma rotina de cuidados que, muitas vezes, foi esquecida ou ignorada. Revelou-se a abertura para o poder-ser-si mesmo, adotando o modo de ser da preocupação e da cura, não apenas no que tange ao autocuidado, mas também ao cuidado ao outro.

O cuidado do enfermeiro para com o homem após uma cirurgia mutiladora na próstata, testículo e pênis, precisa ir além daquele que é realizado durante a hospitalização e o período pósoperatório, sendo, portanto, um desafio. Subsidiar a assistência de enfermagem, pautada na teoria de Orem, possibilita que se realize uma assistência singular e humana, pois busca as características de autocuidado próprias de cada homem e permite contextualizar os aspectos de gênero, culturais e políticos que envolvem esta população, tornando o cuidado mais atentivo e autêntico.

A investigação oferece subsídios ao ensino de Enfermagem no que tange aos aspectos existenciais, humanos, sociais e técnicos sobre o cuidado ao homem, por meio do qual a academia tem a possibilidade de conhecer e aprofundar seus conhecimentos nesse universo, que, por vezes, é ignorada. Sob o olhar da fenomenologia, enfermeiros e profissionais da saúde podem vislumbrar novos caminhos para o cuidado prestado, ultrapassando os saberes técnicos e biológicos adquiridos, contemplando também a dimensão existencial como uma possibilidade de cuidado.

Esta investigação apresenta limitações por ter sido realizada somente com os pacientes de uma unidade hospitalar, além da dificuldade de localizar os participantes devido à mudança dos 


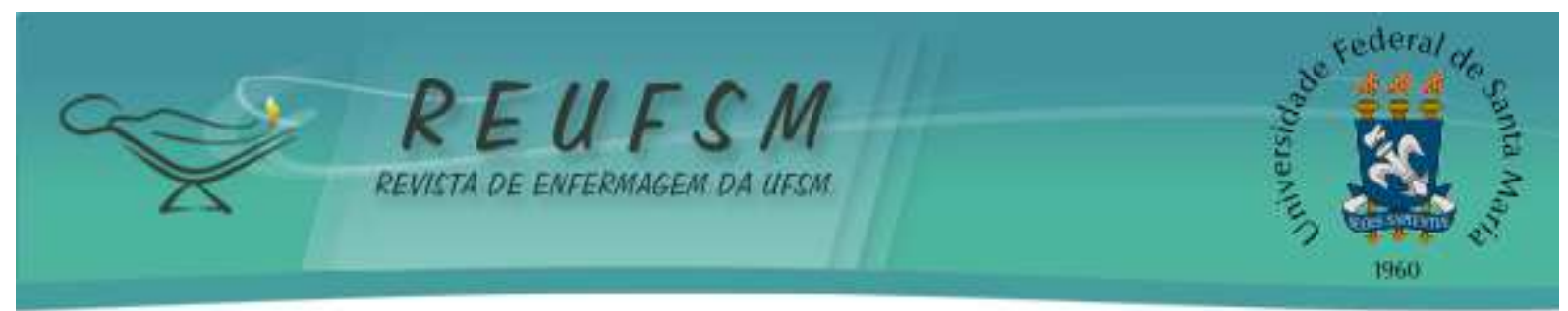

telefones e endereços que constavam nos registros do Serviço de Arquivo Médico do hospital.

Sendo assim, os resultados apresentados constituem a realidade subjetiva de um contexto local.

\section{REFERÊNCIAS}

1. Brasil. Ministério da Saúde. Secretaria de atenção à saúde. Departamento de ações programáticas estratégicas. Política nacional de atenção integral à saúde do homem. Brasília (DF): Ministério da Saúde; 2009.

2. Aguiar RS, Santana DC, Santana PC. A percepção do enfermeiro da estratégia saúde da família sobre a saúde do homem. Rev Enferm Cent-Oeste Min [Internet]. 2015 [acesso em 2017 jul 20];5(3):1844-54.

Disponível

http://www.seer.ufsj.edu.br/index.php/recom/article/view/872/937.

3. Moura MC, Soares CC, Lago EC, Batista MRFF, Oliveira RF, Rocha FCV. Situação da saúde do homem ao buscar os serviços do sistema único de saúde. Rev Interdisciplinar [Internet]. 2017 [acesso em 2018 jan 13];10(1):62-70. Disponível em: https://revistainterdisciplinar.uninovafapi.edu.br/index.php/revinter/article/view/1016.

4. Couto MT, Dantas SMV. Gênero, masculinidades e saúde em revista: a produção da área na revista Saúde e Sociedade. Saúde Soc [Internet]. 2016 [acesso em 2017 jul 20];25(4):857-68. Disponível em: http://www.scielo.br/pdf/sausoc/v25n4/1984-0470-sausoc-25-04-00857.pdf.

5. Barreto MS, Arruda GO, Marcon SS. Como os homens adultos utilizam e avaliam os serviços de saúde. Rev Eletrônica Enferm [Internet]. 2015 [acesso em 2017 nov 10];17(3):18. Disponível em: https://revistas.ufg.br/fen/article/view/29622.

6. Connell R. Masculinities: knowledge, power and social change. Berkeley: University of California Press; 1995.

7. Connell R. The study of masculinities. Qualitative Research Journal. 2014;14(1):5-15.

8. Moreira RLSF, Fontes WD, Barboza TM. Dificuldades de inserção do homem na atenção básica a saúde: a fala dos enfermeiros. Esc Anna Nery Rev Enferm [Internet]. 2014 [acesso 2018 jan. 12];18(4):615-21. Disponível http://www.scielo.br/pdf/ean/v18n4/1414-8145-ean-18-04-0615.pdf.

9. Arruda GO, Marcon SS. Reflexões sobre o cuidado ao homem adulto doente no âmbito familiar: uma perspectiva de gênero. Rev Enferm UFSM [Internet]. 2016 [acesso em 2017 nov. 10];6(2):298-306. Disponível em: https://periodicos.ufsm.br/reufsm/article/view/19344/pdf.

10. Orem DE. Nursing concepts of practice. $5^{\mathrm{a}}$ ed. St. Louis: Mosby; 1995.

11. George B.J. Teorias de enfermagem: os fundamentos à prática profissional. $4^{\circ}$ ed. Porto Alegre(RS): Artmed Editora; 2000.

12. Garcia GS, Palmeira AHA, Silva Jeferson B, Silva Jordânia C. Sistematização da Assistência de Enfermagem ao paciente com câncer de pênis. Rev Univ Vale do Rio Verde [Internet]. 2013 [acesso em 2018 mar 21];11(1):531-41. Disponível em: http://periodicos.unincor.br/index.php/revistaunincor/article/view/989/pdf. 


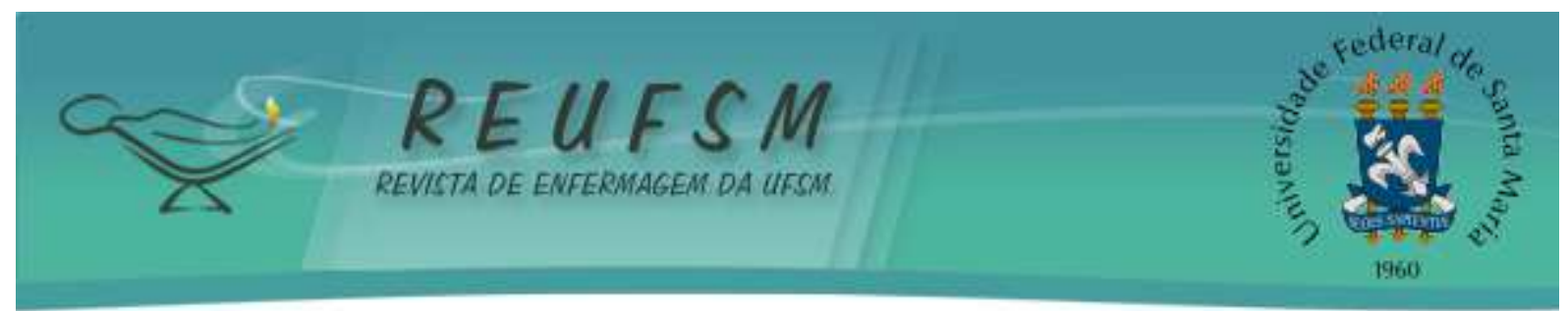

13. Lima RB, Hahn GV. Câncer de próstata e sua relação com a sexualidade masculina: produção científica brasileira. Destaques Acadêmicos [Internet]. 2016 [acesso em 2018 mar 21];8(3):70-86.

Disponível

em:

http://www.univates.br/revistas/index.php/destaques/article/view/1165/1030.

14. Heidegger M. Ser e tempo. $10^{\mathrm{a}}$ ed. Petrópolis (RJ): Vozes, Bragança Paulista (RJ): Editora Universitária de São Francisco; 2015.

15. Brasil. Ministério da Saúde. Conselho Nacional de Saúde. Resolução no 466, de 12 de dezembro de 2012. Diretrizes e normas regulamentadoras de pesquisas envolvendo seres humanos. Diário Oficial da União, Brasília; 2013 jun, 13, seção 1.

16. Salimena AMO, Elias EA, Souza IEO, Vieira LB. Falatório e ocupação no cotidiano das profissionais de enfermagem no cuidado de si e do outro. Rev Baiana Enferm [Internet]. 2016 [acesso em 2017 nov 10];30(1):316-24. Disponível em: https://portalseer.ufba.br/index.php/enfermagem/article/view/14393/pdf_27.

17. Wakiuchi J, Benedetti GMS, Casado JM, Marcon SS, Sales CA. Sentimentos compartilhados por acompanhantes de pacientes oncológicos hospedados em casas de apoio: um estudo fenomenológico. Esc Anna Nery Rev Enferm [Internet]. 2017 [acesso em 2017 nov 10];21(1):1-8. Disponível em: http://www.scielo.br/pdf/ean/v21n1/1414-8145-ean21-01-e20170011.pdf.

18. Rangel EM, Moraes LP, Castro BGSMM. "Porque eu sou é home!": Uma análise dos impactos da construção social da masculinidade no cuidado com a saúde. Interfaces Cient Hum Soc [Internet]. 2017 [acesso em 2018 mar 21];6(2):243-52. Disponível em: https://periodicos.set.edu.br/index.php/humanas/article/view/4517/2454.

19. Silva SED, Xavier ECL, Vasconcelos EV, Araújo JS, Alves PS, Cunha NMF, et al. Câncer de Pênis: sob a ótica da representação social de pacientes submetidos à amputação de pênis e suas implicações para o cuidado de si. Interfaces Cient Hum Soc [Internet]. 2014 [acesso em 2018 mar 21];2(1):39-46. Disponível em: https://periodicos.set.edu.br/index.php/saude/article/view/1624/1002.

20. Vasconcelos AG, Pessoa VLMP, Menezes FWP, Florêncio RS, Frota MXF. Repercussões no cotidiano dos pacientes pós-transplante cardíaco. Acta Paul Enferm [Internet]. 2015 [acesso em 2018 mar 21];28(6):573-9. Disponível em: http://www.redalyc.org/pdf/3070/307043975012.pdf.

Data de submissão: 30/11/2017

Data de aceite: 20/04/2018

Autor correspondente: Rafael Carlos Macedo de Souza

E-mail: rafaelcarlos_souza@hotmail.com

Endereço: Rua Marechal Cordeiro de Faria, 172, Bairro Carlos Chagas, Juiz de Fora, MG/Brasil. CEP: 36.081 .330 